\title{
O BLOCÓDROMO ESTÁ NA RUA: A APROPRIAÇÃo MERCADOLÓGICA E OS BLOCOS DE CARNAVAL DA CIDADE DO RIO DE JANEIRO
}

\author{
Tiago Luiz dos Santos Ribeiro \\ Programa de Pós-Graduação em Artes, Instituto de Artes, Universidade do Estado do Rio de Janeiro, Brasil \\ Felipe Ferreira \\ Centro de Referência do Carnaval, Instituto de Artes, Universidade do Estado do Rio de Janeiro, Brasil
}

\begin{abstract}
RESUMO
A partir da proposta da Prefeitura da Cidade do Rio de Janeiro de criar uma arena para desfile de blocos carnavalescos, para o carnaval de 2018 , projeto que ficou conhecido como "Blocódromo", visamos identificar que aspectos deste empreendimento - que não saiu do papel - ganharam vida no carnaval de 2019. Para tanto, abordaremos esta manifestação carnavalesca como objeto de ressignificações na sociedade contemporânea, o que se revela de modo evidente nos variados estágios de reformulação do projeto Arena Carnaval Rio, tanto em 2018 (o que inclui mudanças estruturais e de data) como em 2019, quando recebeu um outro formato, cuja implementação esbarrou em novos processos de negociação. A partir daí, utilizando alguns blocos de carnaval, analisaremos a ideia de apropriação destes grupos como produtos de interesse mercadológico, tanto por empresas privadas quanto pelo poder público, destacando questões como a perda de controle sobre práticas culturais assim como os efeitos da mercantilização e turistificação do carnaval carioca. Através das tensões e diálogos entre os diversos atores envolvidos observaremos como este tipo de organização carnavalesca desafia o projeto de ordenação da festa, por meio das disputas de poder nas vias públicas, enquanto se revela uma atraente fonte de receita.
\end{abstract}

\section{THE BLOCÓDROMO IS OUT: THE MARKET TAKEOVER AND THE STREET PARADES IN RIO}

\begin{abstract}
Starting from the proposal of Rio de Janeiro's City Hall to create an arena for the carnival parades in 2018 known as "Blocódromo", this work aims to identify which aspects of this venture - which remained aspirational - came to life in 2019's carnival. To do so, this carnival manifestation will be approached as an object of re-signification in contemporary society, which is evident in the varied reformulation stages of the Rio Carnival Arena project, both in 2018 (which includes structural and date changes) as in 2019, when it received another configuration, which involved new negotiation processes in order to be implemented. Henceforth, using street carnival parades as an example, this project will analyse the idea of appropriation of these groups as products of market interest, both by the private and public sectors, highlighting issues such as loss of control over cultural practices as well as the effects of commodification and growth of tourist flow in Rio's carnival. Through the tensions and debates between the various
\end{abstract}


stakeholders this work aims to observe how this type of carnival organization challenges the event's organization as a whole, considering the power struggles on public roads while it proves to be an attractive source of revenue.

\section{KEYWORDS}

carnival; street carnival parades; appropriation; tourist flow

\section{INTRODUÇÃo}

Manifestação carnavalesca centenária, a nomenclatura "blocos de carnaval" compreende grupos diversos que, já em meados do século XIX, se misturavam às muitas outras formas de festejar o período que antecede a quaresma, sendo chamados quase indistintamente de "grupos", mas também aleatoriamente de "clubes", "cordões", "ranchos" ou "sociedades" (Ferreira, 2004, p. 207), o que revela a difícil tarefa de se apontar a data de surgimento dos mesmos. Ao longo dos anos, estes grupos adquiriram características próprias, diferenciando-se de outras brincadeiras carnavalescas, através de diversas influências e interesses, permanecendo em constante processo de ressignificação.

Durante o século $X X$, as variadas agremiações classificadas como blocos de carnaval também foram se agrupando e se subdividindo, formando as diferentes categorias que conhecemos hoje. Araújo (2003) aponta que entre estes grupos estão: os blocos de enredo (conjuntos com estruturas bem próximas às das escolas de samba, que desfilam em competição, em um local específico), os blocos de embalo ou empolgação (estruturados seguindo o modelo de blocos simples, sem variação de fantasias, alegorias ou enredos, mas que também se subdividem em grupos e séries. Dentre os representantes desta categoria estão o Bafo da Onça, o Cacique de Ramos e o Boêmios de Irajá, que desfilam hors concours) e os chamados blocos de sujo (conjuntos mais simples de foliões, não-dramatizados, sem fantasias elaboradas e sem alegorias).

O presente trabalho tem como objeto de estudo uma destas categorias, chamada bloco de rua, que compreende agremiações de diferentes públicos e propostas musicais, estéticas e de modelos de desfile, que podem também ser chamados de cordões ou bandas. Seja através de cortejos ou parados; utilizando trios elétricos, carros de som ou nenhum artifício de microfonagem; embalados pelos mais diversos ritmos; sugerindo fantasias aos seus desfilantes ou não. Em suma, grupos distintos que compartilham como categoria comum a flexibilidade de regras quanto ao formato, local de desfile e de livre participação.

Agremiações de evidente sucesso no Rio de Janeiro no século XXI (Barros, 2013; Herschmann, 2013), os blocos de rua do carnaval carioca (que não desfilam em competição) atraem não só a presença de milhões de foliões como também o interesse da publicidade, além de uma boa dose de preocupação da Prefeitura da cidade. Apontadas como importante ferramenta para a atração de turistas à cidade (Boschi, 2007), estas organizações carnavalescas têm se submetido a normas e procedimentos a partir do 
decreto municipal $n^{\circ}$. 30659, de 7 de maio de 2009, incluindo restrição de horários de desfiles, mudanças de locais dos cortejos e indeferimento na autorização de desfiles.

Foi neste cenário que a proposta de se erguer um "blocódromo", espécie de Sambódromo' para blocos, começou a ganhar forma. Iniciativa da Prefeitura, a chamada Arena Carnaval Rio, idealizada em 2017, propunha levar os desfiles de blocos carnavalescos para o Parque dos Atletas - área criada para o lazer dos atletas que disputaram as Olimpíadas de 2016 e que ao longo dos anos recebeu eventos musicais, incluindo três edições do Rock in Rio -, no afastado bairro da Barra da Tijuca. O projeto logo serviu para suscitar questões como a disputa pelo espaço público, assim como os efeitos do deslocamento dos blocos de carnaval na organização da folia da cidade, além do uso mercadológico desta manifestação.

Projeto malfadado, que tentou sobrevida em 2019, sendo novamente engavetado, o blocódromo surge como um novo paradigma do que Storey (2015, p. 30) define como um terreno de trocas e negociações que definem a cultura popular. Entendendo estas relações sociais de forma complexa, sob a interação de diversos atores sociais (Canclini, 2008), visamos avaliar como algumas premissas da Arena Carnaval Rio se perpetuaram e de que maneira as reformulações pelas quais o projeto passou revelam o terreno de disputas de poder em que os blocos carnavalescos estão inseridos.

A metodologia deste trabalho se ampara em pesquisa bibliográfica e documental em livros e artigos, entrevistas com representantes dos blocos carnavalescos e observação participante. Além disso, por abordar um tema tão recente, destacamos a importância dos acervos de jornais na web, privilegiando O Globo - por sua importância dentre os tabloides da cidade e por sua extensa cobertura dos carnavais do período -, além de outros periódicos consultados através da Hemeroteca Digital da Biblioteca Nacional, através da qual foram sondadas todas as menções ao termo "blocódromo".

Deste modo, estruturamos este artigo em três partes, buscando apresentar a proposta do Blocódromo (ou Arena Carnaval Rio) sob três aspectos ou fases: a primeira, a premissa do projeto, anunciado em dezembro de 2017, que traduz o modo como o poder público enxerga os blocos; a segunda, o conflito discursivo diante da proposta, que envolveu questões como a disputa de poder no espaço público e a mercantilização da festa; e a terceira, que revela a capacidade de negociação dos atores envolvidos, demonstrada nas reformulações do projeto e diálogo com os blocos.

Observamos, desse modo, como estas organizações negociam com o interesse mercadológico que se sobrepõe em propostas como a do Blocódromo, apropriando-se da potência dos blocos carnavalescos ao mesmo tempo em que pode-lhes servir como aquilo que Ferreira (2012, p. 151) classifica de estratégia de sobrevivência.

1 Inaugurado em fevereiro de 1984 e localizado no Centro do Rio de Janeiro, o Sambódromo é uma passarela fixa para a realização dos desfiles de escolas de samba da cidade. Antes dele, os desfiles foram realizados em diversas ruas e avenidas cariocas (Araújo, 2003). 


\section{O BLOCÓDROMO - A PROPOSTA}

Em 2011, Zuenir Ventura, discorrendo sobre o papel do Sambódromo para a organização dos desfiles das escolas de samba, afirmou que algo deveria ser feito para ordenar as apresentações dos blocos de carnaval e impedir o "vandalismo e o emporcaIhamento da cidade", mas registrava que "a não ser um louco, ninguém proporia confinar os blocos num blocódromo" (Ventura, 2011, p. 7). Em 26 de dezembro de 2017, um projeto chamado Arena Carnaval Rio (figura 1) foi apresentado pela Prefeitura da cidade do Rio de Janeiro com o intuito de abrigar apresentações de blocos de carnaval (Bacelar, 2017, p. 5). A ideia logo recebeu como apelido o mesmo termo utilizado pelo jornalista, anos antes: Blocódromo.

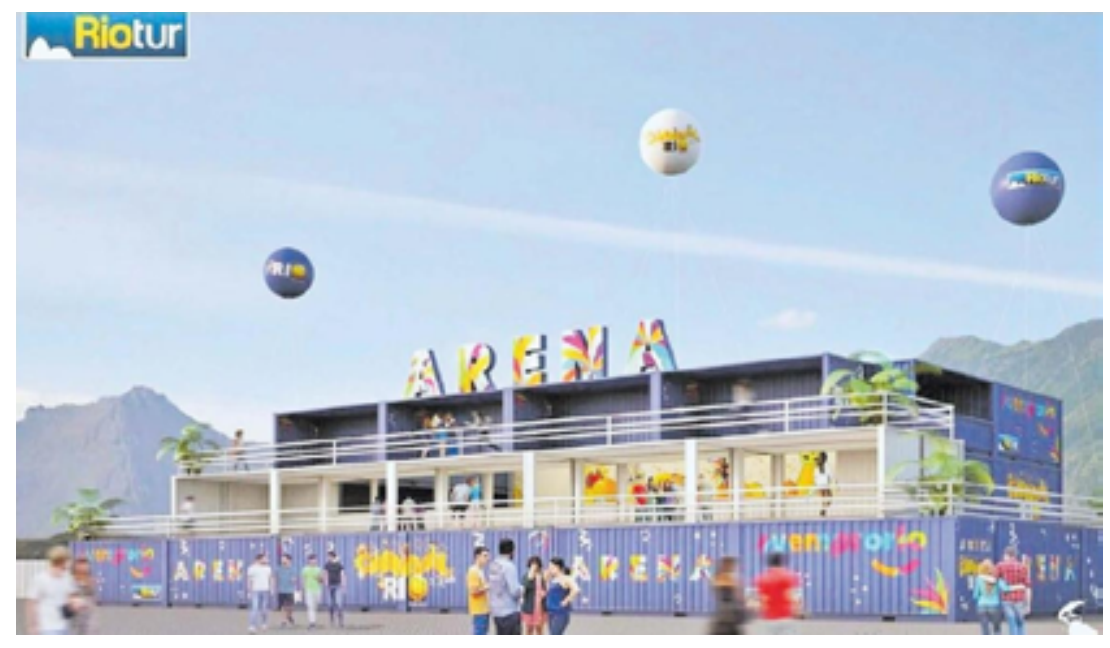

Figura 1: Projeto da Arena Carnaval Rio, no Parque dos Atletas (Bacelar, 2017, p. 5)

A proposta, segundo o comunicado divulgado no Diário Oficial do Município de 12 de janeiro de 2018 (p. 33), era a de promover cinco dias de shows de samba e pagode em um palco fixo, apresentações de trios elétricos e DJs, além dos desfiles de 10 blocos $^{2}$, dois por dia, do sábado de carnaval até a quarta-feira de cinzas. Localizado no Parque dos Atletas, na Barra da Tijuca, a Arena Carnaval Rio teria entrada gratuita, com acesso controlado por catracas eletrônicas para a contagem do público e capacidade diária para 100 mil pessoas, embora a estimativa da Riotur (órgão da Secretaria Especial de Turismo da cidade do Rio de Janeiro) fosse de 20 a 40 mil foliões por dia.

De acordo com Boere e Magalhães (2018, p. 10), a Arena utilizaria o serviço de cordas para separar o público dos trios elétricos (esquema semelhante ao empregado no carnaval de Salvador) e ainda teria uma área VIP com direito a 20 mesas bistrô, 80 banquetas altas, quatro sofás de dois lugares e 64 pufes, onde seriam servidos canapés quentes e frios para as 300 pessoas que ganhariam pulseirinhas de acesso. $O$ custo do projeto, de acordo com os editais de licitação, era estimado em mais de um milhão e 400 mil de reais em cenografia e infraestrutura e mais de um milhão e 800 mil em

2 Segundo Saconi (2018, p. 10) os blocos Bangalafumenga e Sargento Pimenta estavam confirmados na programação desde o primeiro momento. 
produção, organização e coordenação (Diário Oficial do Município do Rio de Janeiro, 12 de janeiro de 2018 , p. 90)3.

\section{O BLOCÓDROMO - O CONFLITO}

Não demorou muito para que a ideia de um Blocódromo provocasse uma enxurrada de críticas. Para se ter uma ideia, antes mesmo da publicação no Diário Oficial do Município, a notícia já havia circulado pela imprensa, que estampava uma série de questionamentos sobre o projeto. Em reportagem da Folha de São Paulo (Rangel, 2017, p. B7), enquanto o presidente da Riotur, Marcelo Alves, afirmava que "a cidade tem que estar preparada no carnaval para quem curte e também para os que querem aproveitar os dias sem ir aos blocos", a presidente da Sebastiana (Associação de Blocos Independentes da Zona Sul, Santa Teresa e Centro do Rio), Rita Fernandes, rebatia: "estamos [nas ruas] há 30 anos e nunca deu errado. O presidente da Riotur não pode mudar a regra sem conversar". Ainda segundo a publicação, a iniciativa dialogava com outras propostas de ordenação da festa, como a proibição de desfiles de blocos nas ruas internas do Leblon (concentrando os cortejos na praia).

Logo os representantes de outras ligas ${ }^{4}$ dos blocos, como a Amigos do Zé Pereira (que reúne oito agremiações do Centro e da Zona Sul), também se manifestaram contra o projeto da Arena. Estas ligas, que representam grandes blocos, como o Simpatia é Quase Amor e Orquestra Voadora, temiam que a proposta decretasse o fim da espontaneidade do carnaval de rua. Por sua vez, a Riotur garantia que a intenção era a de oferecer "uma opção a mais de lazer, mais confortável, numa área com banheiros fixos e contêineres com bebidas e lanches" (Bacelar, 2017, p. 5).

Para podermos entender as questões relacionadas ao projeto da Arena Carnaval Rio, nos parece importante observar que a ideia de se confinar o desfile de blocos num local isolado não era uma novidade, logo, sua premissa se justificava em um interesse já estabelecido, o de definir um espaço exclusivo para o carnaval de rua. Organizadora e mentora de um dos maiores blocos do carnaval carioca, o Bloco da Preta, a cantora Preta Gil afirmou que, em 2015, durante a preparação do seu desfile, já havia sugerido o blocódromo ao então prefeito do Rio de Janeiro, Eduardo Paes (Caruso, 2018, p. 2). Antes disso, em 2011, o Caderno de Opinião de O Globo havia estampado a mesma proposta, como sugestão do leitor Sylvio Pélico, numa edição em que mensagens dos leitores sobre o carnaval recém terminado ocuparam quase que uma página inteira da publicação com reclamações ao direito de ir e vir, críticas ao excesso de bebidas e ao ato de urinar em público, além de sugestões de mudanças de locais de desfiles e de limitação do número de blocos, em discursos que incluíam argumentos nostálgicos e criticavam a discrepância entre o grande público dos blocos em relação às manifestações políticas esvaziadas (Filho, 2011, p. 8).

${ }^{3}$ Retirado de http://doweb.rio.rj.gov.br

${ }^{4}$ As chamadas ligas de blocos de carnaval são agrupamentos de blocos carnavalescos formados por agremiações com interesses em comum e/ou pela proximidade geográfica de seus afiliados, que se reúnem na intenção de obterem uma maior participação nas decisões relacionadas a estas manifestações carnavalescas. 
Nos jornais (através da base de dados da Hemeroteca Digital da Biblioteca Nacional), a primeira menção a um Blocódromo aparece no ano de 2006, mas de modo diferente da proposta aqui apresentada. O termo foi utilizado para designar a ideia de circuitos exclusivos para os desfiles e não um espaço único para os blocos. A sugestão era de Ana Maria Maia, na época ocupando o cargo de Subsecretária Municipal de Eventos, que, segundo o Jornal do Brasil, prometia discutir a questão com o então prefeito César Maia (Marta, 2006, p. A14). Apesar de não ser possível afirmar que esta foi a primeira ideia neste sentido - uma vez que alguma proposta semelhante possa ter surgido antes, com outro nome -, é interessante observar como só encontramos o termo blocódromo mais de 20 anos após a criação do projeto que de algum modo the serve de inspiração: o Sambódromo. Por outro lado, a primeira década do ano 2000 coincide com o período em que se estabelecia a ideia de um suposto renascimento dos blocos de carnaval - discurso defendido por Motta (2011, p. 13).

Esta busca pela origem do termo blocódromo permite-nos afirmar que a ideia de um espaço controlado para os blocos de carnaval não surgiu do dia para a noite. Para tanto, revela-se interessante a abordagem de autores como Barros (2013, pp. 10-11), que associam este tipo de manifestação carnavalesca - marcada pela multiplicidade de características, reunindo agremiações de diferentes propostas - com a imagem de "liberdade" de regras em oposição ao "exemplo de organização interna" das escolas de samba. Neste mesmo sentido, Leopoldi (2010, p. 27) aponta que o "crescimento acelerado" do número de blocos que se apresentam no carnaval do Rio de Janeiro é visto como o "renascimento da carnavalização" contra a crescente formalização do desfile das escolas, que teriam se afastado do "espírito carnavalesco original sintonizado com as festas bakhtinianas".

Apesar de contestável, esta ideia de retomada do carnaval de rua - respaldada, segundo Ferreira (2018, p. 51), pela diminuição de referências a esta manifestação carnavalesca na imprensa em meados do século $X X$, o que esconde o efeito de espraiamento dos lugares carnavalescos pelo subúrbio da cidade, estimulado, em alguma medida, pelos concursos de coretos e batalhas de confete em vários bairros, como apontado por Guimarães (2011, p. 260) - reflete-se em projetos de ordenação da festa de rua. Para Ferreira (2012), estas narrativas de "morte" e "renascimento" do carnaval existem desde que a festa nasceu, reflexo de uma intenção de normatização da folia, um discurso que releva o que se esperar de manifestações carnavalescas deste tipo. Neste sentido, é imprescindível observar a disputa pelo espaço público das áreas nobres da cidade como fator determinante para o desenvolvimento de projetos como o blocódromo.

Em seu estudo sobre os diferentes modos de vivência carnavalesca na cidade do Rio de Janeiro, Queiroz (1999, p. 106), abordando a ideia estabelecida da Zona Sul como a área da "sociedade ordeira" e a Zona Norte como o habitat da "sociedade perigosa", destaca que a disciplina dos desfiles das escolas de samba seria resultado da interação destas duas divisões sociais e uma prova da hegemonia das camadas superiores e da submissão das inferiores (p. 107) ou, como a autora define, a domesticação da massa urbana (p. 71). Neste sentido, o crescimento do número de blocos na Zona Sul da 
cidade, ou seja, a ampliação da presença de uma manifestação carnavalesca menos marcada por regras numa área mais "organizada" da cidade, provocaria conflitos e busca por soluções.

Vale observar que esta disputa pelo espaço público já faz parte da história do carnaval carioca. No período colonial, por exemplo, as ruas ocupadas pelos escravos e evitadas pela elite já marcavam a forte separação entre os tipos de entrudo, o popular e o familiar 5 . Com as mudanças ocorridas a partir da chegada da família real ao Brasil, em 1808, o tecido urbano carioca começava a ser disputado por membros da nobreza portuguesa, pela elite brasileira e por homens livres e escravos que passavam a usar e significar os espaços da cidade de formas diferentes, o que levou a burguesia a procurar ocupar as ruas do Centro com um novo carnaval, visando desqualificar a antiga festa do entrudo (Ferreira, 2012, pp. 55-56). Ainda de acordo com Ferreira (2004, p. 165), já em 1857 um texto do Jornal do Commercio, de 23 de fevereiro, sugeria que se determinasse "um certo número de ruas para o passeio", uma vez que, segundo o autor, "começava a ficar cada vez mais clara a necessidade de algum tipo de providência para dar um mínimo de organização à confusão carnavalesca que, no Rio de Janeiro, atingia um nível nunca imaginado". Todas essas tentativas de ordenação da festa nos revelam o que as classes dominantes entendiam como o "verdadeiro carnaval".

No caso aqui abordado, além da "problemática" ascensão do carnaval de rua na Zona Sul, onde "deveria" reinar a ordem, outras questões também podem ter influenciado. Segundo Amar (2018, p. 114), já ao final dos anos 1990, revelava-se uma mudança no modo de ver a folia carioca, quando uma nova coalisão de grupos de interesse paraestatal retirou os dólares de turismo dos espetáculos do Carnaval:

uma nova visão, revanchista e obcecada por respeitabilidade, do turismo apropriado para o Rio e para a identidade nacional surgiu e julgava, envergonhada, o projeto utópico de nacionalismo populista cultural da Lapa e do Carnaval do início do século XX, que focava na mistura racial e em uma modernidade sensualizada. As elites (...), constrangidas e em significativo diálogo com grupos cristãos evangélico-pentecostais, começaram a ver a imagem tropical e sensual do Brasil como falsa, suja e vulgar. Eles achavam que isso pervertia e prostituía a nação na economia global.

Neste sentido, os blocos de carnaval poderiam se enquadrar no que Amar (2018, p. 97) chama de "inimigos culturais":

certas parcelas da sociedade ficaram estigmatizadas como inimigas culturais da nação em processo de modernização e como consequências nefastas do desenvolvimento globalizado. Essa agenda jogou luz sobre determinados sujeitos e os declarou responsáveis pelas inseguranças urbanas associadas à globalização.

\footnotetext{
${ }^{5}$ Enquanto dentro das casas a elite se divertia com os limões de cheiro - pequenas bolas de cera recheadas de perfumes ou vinhos - nas ruas os escravos e as pessoas das classes populares participavam de brincadeiras bem mais agressivas, em que aos limões ou laranjas de cheiro se juntavam todo tipo de projéteis ou líquidos mais imundos (Ferreira, 2012, p. 55).
} 
Abordagens como estas dialogam com as mudanças desencadeadas após o decreto municipal $n^{\circ} 30659$ de 7 de maio de $2009^{6}$, em que a Prefeitura da Cidade do Rio de Janeiro implementava novas normas e procedimentos para o carnaval de rua do município, restringindo horários e locais de desfile. Embora esta não seja a primeira iniciativa deste tipo - nos anos 1950, por exemplo, aos sábados de carnaval, o jornal O Globo estampava o que era proibido e permitido pela polícia nos dias de folia, o que incluía diretrizes sobre os blocos -, o novo decreto coincidia com o momento em que os olhos do mundo se viravam para a cidade do Rio de Janeiro, que se preparava7 para a realização da Copa do Mundo de $2014^{8}$ e dos Jogos Olímpicos e Paralímpicos de $2016^{9}$. Deste modo, a ideia de um Blocódromo, com acesso controlado por catracas eletrônicas e área VIP, na Barra da Tijuca (nova área nobre da cidade), se revelava como mais uma etapa deste processo.

Rita Fernandes, presidente da Sebastiana, falou, na época, que o perfil do carnaval carioca é outro e que não acreditava que ele tenha que ficar confinado a qualquer tipo de arena: "entendemos que grupos que fazem show se interessem em ir pra lá. Mas esse tipo de iniciativa jamais poderia substituir o carnaval de rua. Somos contra transformar a Arena no modelo do carnaval". Seguindo a mesma linha, Rodrigo Rezende, presidente da Liga Amigos do Zé Pereira, via a iniciativa com desconfiança: "a gente tem muito medo de que a Prefeitura queira segregar o carnaval de alguma forma" (Bacelar, 2017, p. 5).

Essa não seria a primeira vez que a Barra da Tijuca se tornava um destino desejado para o carnaval. Em 1981, por exemplo, segundo o Jornal do Brasil (Informe JB, 1981, p. 6.), João Roberto Kelly, então presidente da Riotur, chegou a propor a mudança dos desfiles da Marquês de Sapucaí para o antigo Autódromo de Jacarepaguá, local em que hoje se encontra o Parque Olímpico. Da mesma forma, Anísio Abraão David, presidente de honra da Beija-Flor, nunca escondeu sua vontade de levar as escolas de samba para a Barra (Prestes Filho, 2015, p. 20). Vale salientar que estas propostas buscavam "desafogar" o Centro do Rio, optando por um bairro até então pouco ocupado, com ruas mais largas e planejadas.

Desta vez, sobre a escolha da Barra da Tijuca para sediar a Arena Carnaval Rio, a Riotur afirmava buscar um novo atrativo para a Zona Oeste carioca, por dispor de opções de transporte público que a conectam com toda a cidade, oferecendo um reforço

\footnotetext{
${ }^{6}$ Composto de 16 artigos, o documento estipulava horários de concentração e término de desfiles para blocos e bandas, mediante requerimento solicitado no ano anterior a sua realização. Estas autorizações estariam condicionadas ao parecer da Companhia de Engenharia de Tráfego do Rio de Janeiro (CET RIO), ao nada a opor das Coordenadorias das Áreas de Planejamento (Subprefeituras) e à regularização da exposição de marcas de patrocinadores junto à Coordenação de Licenciamento e Fiscalização. Além disso, ficou estabelecido que caberia a cada bloco a responsabilidade pelo recolhimento dos direitos autorais junto ao Escritório Central de Arrecadação - ECAD. O não cumprimento das normas por parte das bandas e blocos carnavalescos implicaria o indeferimento do pedido para o carnaval do ano subsequente.
}

${ }^{7}$ Além das obras realizadas (que valorizaram áreas como o Centro da cidade, local de tradicional ocupação dos blocos de carnaval) a preparação para estes grandes eventos trouxe também mudanças no programa de segurança pública, destacando-se a implantação do programa das UPPs (Unidade de Polícia Pacificadora), iniciado em 2008, e que dialogava com a ideia de policiamento calcado na "qualidade de vida" apontado por Amar (2018).

${ }^{8} \mathrm{O}$ anúncio do Brasil como sede da Copa do Mundo foi realizado em 30 de outubro de 2007.

9 O anúncio do Rio de Janeiro como sede dos Jogos Olímpicos e Paralímpicos de 2016 foi realizado em 2 de outubro de 2009. 
para a ocupação hoteleira da região (afastada da maior parte dos eventos carnavalescos) e ocupando o Parque dos Atletas, área ociosa na maior parte do ano após os Jogos Olímpicos e Paralímpicos de 2016 (Diário Oficial do Município do Rio de Janeiro, 12 de janeiro de 2018 , p. $33^{10}$ ). Uma ideia que, assim como a de transferência do Sambódromo para a Barra da Tijuca, ignorava as transformações culturais acarretadas com este deslocamento.

No caso da Arena Carnaval Rio, a Prefeitura negava que a intenção seria a de remanejar os blocos para o novo espaço, mas, sim, realizar uma espécie de segunda apresentação (Bacelar, 2017, p. 5). Porém, há de se supor que, como o evento ocorreria durante o carnaval, a primeira ideia seria, ao menos em parte, efetivada. Basta deduzir que muitos foliões que optassem por frequentar o Blocódromo deixariam de estar presentes nos blocos de outras regiões, o que reduziria seu público. Além disso, levar estes foliões para a Barra da Tijuca indicava uma maneira de alterar a geografia da festa, já que a região da Zona Oeste, que abriga o bairro, seria a área com a menor quantidade de desfiles oficiais de blocos de carnaval em 2018, segundo listagem da própria Riotur"1.

Além disso, existem outras questões envolvidas nesta mudança de lugar da festa, saindo do espaço público cotidiano para uma área exclusiva preparada para um evento. Em seu trabalho sobre a rua como palco, Schechner (2012, pp. 157-180) ressalta que "permitir que as pessoas se reúnam nas ruas é sempre flertar com a possibilidade de improvisação - o inesperado pode acontecer". Ciente disso, o Estado, temendo o caos, busca domesticar a festa transformando o que era inversão da ordem social num espeIho dela mesma. Deste modo, a folia nas ruas, tomando de assalto lugares que "refletem história" e "irradiam poder" é uma afirmação de algo que o statu quo pretende evitar.

Para Ferreira (2018), os blocos carnavalescos atuais, como uma espécie de "cordões contemporâneos", trazem novas tensões e sentidos para o carnaval das ruas, onde acontecem as disputas que, segundo ele, caracterizam o carnaval carioca:

brincar carnaval não é simplesmente tocar música, usar fantasia e cantar. É reivindicar o espaço público para a folia e transformar a rua cotidiana, por onde passa o trânsito, em avenida festiva através, aí sim, de músicas, fantasias, cantorias e outras formas de transgressão simbólicas. (...) Há tempos nossos foliões entenderam o valor dessa batalha que vem ocupando as artérias da cidade desde o período colonial, com os entrudos, e, mais tarde, as sociedades carnavalescas, cucumbis, zé pereiras, cordões, ranchos, blocos e escolas de samba. O fenômeno atual dos novos blocos é só o capítulo mais recente dessa longa história. (Ferreira, 2018, p. 19)

Seguindo a mesma linha de pensamento, o arquiteto Sérgio Magalhães revela a importância destas disputas pelo espaço público para a sua vitalidade:

\footnotetext{
${ }^{10}$ Retirado de http://doweb.rio.rj.gov.br

"Na lista oficial de blocos do carnaval de 2018, divulgada pela Prefeitura do Rio de Janeiro, a Zona Oeste realizaria 122 desfiles de blocos, contra 127 do Centro, 147 da Zona Sul e 200 da Zona Norte.
} 
onde o incrível fenômeno dos blocos festeja o carnaval? Na rua, no espaço público. Uma praça, todos sabemos, é uma área livre, pública, cercada de construções. Mas fosse apenas edifícios + área livre, seria uma imensa maquete. É o uso que a qualifica. Isto é, o espaço urbano é o material e o espiritual somados na história, construindo a memória e a identidade coletivas. Os cidadãos se reconhecem como parceiros ao compartilharem imagens e memórias. A identidade coletiva cimenta valores e permite que o embate quotidiano se estabeleça em bases mutuamente aceitas. É um verdadeiro acordo social promovido pelo usufruto dos bens culturais, dos espaços e dos signos coletivos. (...) O espaço urbano é vida e estabilidade; somos nós e nossa vivência no lugar, que nos somamos às gerações precedentes na construção da identidade e da memória comuns. (Magalhães, 2011, p. 7)

Neste sentido, ainda para Ferreira, a criação do Blocódromo mal esconde a tentativa de esvaziar esta potência política e transgressora de ressignificar a rua, propondo um território higienizado, organizado e delimitado, transformando o que era folia em um espetáculo espacialmente controlável. Em suas palavras:

os blocos precisam escrever sua diversidade no asfalto das ruas, umas sobre as outras, como grafites imaginários que se sobrepõem numa espécie de obra de arte coletiva (...) A tentativa de encurralar e controlar esse ímpeto está fadada ao inferno das boas intenções que, parece, buscam agradar àqueles que veem no carnaval uma boa oportunidade para ficar na cama até mais tarde. Enfim, se a ideia é arrumar um espaço reservado para os blocos, que os foliões, aliás, nunca pediram, por que não pensar carnavalescamente e transformar o Blocódromo num lugar vazio e silencioso feito para acolher quem quer ficar longe do carnaval - um "Descansódromo" - e deixar as ruas da cidade para os foliões? (Ferreira, 2018, p. 19)

Trata-se, portanto, de uma disputa de significação do espaço público, do que ele é e pode ser, uma contenda discursiva que parece estável em alguns momentos, enquanto volta a efervescer em outros, como o carnaval. Um processo que, como aponta Storey (2015, p. 421), revela a cultura não como algo "autêntico", nem imposto, mas um "equilíbrio de ajustes" entre ambos, mistura contraditória de forças que vêm de "baixo" e de "cima", "locais" e "globais", marcadas pela "resistência" e "incorporação". Neste cenário, é importante salientar os diversos atores envolvidos e observá-los como sujeitos de diversas origens, que agem sob vários interesses, o que nos permite observar estas questões de modo mais amplo, menos maniqueísta. Exemplo disto são os representantes dos próprios blocos que se revelam conscientes dos transtornos que um desfile pode causar.

Em uma discussão proposta pelo $O$ Globo (Fernandes, 2014, p. 12) sobre a alteração de roteiro dos blocos de carnaval, Rita Fernandes, presidente da Sebastiana, não nega que nos últimos anos surgiram blocos que "não têm relação geográfica com seu 
entorno" e que alguns se tornaram gigantescos, mas registra que blocos tradicionais, com seus 20, 30, 50 anos de história, não podem ser punidos na "vã alegação de que a cidade não suporta". E continua:

como tirar o Simpatia é Quase Amor e a Banda de Ipanema do bairro em que nasceram e que thes serve de inspiração? Como imaginar o Suvaco do Cristo fora do Jardim Botânico? A Banda do Leme sem o Leme? Como separar o Escravos da Mauá da Zona Portuária? Esses blocos têm uma estreita, intrínseca e profunda relação com suas localidades. Seus roteiros não são à toa, não surgiram do nada. Há razões que todos deveriam conhecer, afinal estamos falando da história do nosso lugar.

Discursos como este apontam o problema de se observar os blocos de carnaval como uma categoria homogênea, uma vez que, diante de tensões (como o embate com os órgãos públicos), revelam rivalidades entre as próprias agremiações. Seria o local de fundação do bloco ou o tempo de história do mesmo o fator determinante para a permissão do seu desfile, como aponta a fala de Rita Fernandes? Para alguns grupos, como o Cordão do Boi Tolo, não. Segundo um de seus fundadores, Luís Almeida'2, os blocos têm o direito de estar na rua amparados no artigo 5, parágrafo XVI, da Constituição Federal, que permite "reunir-se pacificamente, sem armas, em locais abertos ao público, independentemente de autorização". Do mesmo modo, enquanto o Boi Tolo prefere não monetizar com os seus desfiles e nem se apresentar em lugares privados, outros grupos como o Minha Luz é de Led, formados por músicos profissionais, promovem festas ao longo do ano com cobrança de ingressos visando, segundo seu fundador, Arthur Ferrei$\mathrm{ra}^{13}$, a valorização de sua marca.

Estes variados formatos e propostas de blocos carnavalescos também se refletem nas diferentes posturas destas agremiações diante de questões como o merchandising nos desfiles, o patrocínio no carnaval e o próprio Blocódromo. Deste modo, percebemos que este não é um embate binário: de um lado os blocos, de outro a Arena Carnaval Rio. Para além do que já foi aqui discutido, é importante observar que a ideia do Blocódromo não diz respeito apenas ao modo como a Prefeitura enxerga a festa, mas também sobre como os blocos compreendem as suas atividades, enxergam suas próprias características e sua capacidade de resistência e incorporação.

É neste cenário que Storey (2015, p. 178), citando Stuart Hall, vai classificar a cultura como um terreno de lutas ideológicas cujo resultado se dá através da articulação. É de se salientar, também, o contraste entre os valores milionários que seriam investidos na Arena Carnaval Rio e a falta de apoio financeiro aos blocos de rua, como apontado pelos representantes das ligas Sebastiana e Amigos do Zé Pereira. Se, de acordo com a Prefeitura, os recursos do projeto viriam de patrocinadores, segundo O Globo (Boere \& Magalhães, 2018, p. 10), os editais informavam que a verba era oriunda da chamada

\footnotetext{
${ }^{12}$ Em entrevista ao autor deste trabalho, em 19 de dezembro de 2018, por email.

${ }^{13}$ Em entrevista ao autor deste trabalho, realizada por e-mail em 18 de dezembro de 2018.
} 
fonte 100 da Prefeitura, ou seja, recursos próprios, justamente num período em que a municipalidade afirmava lidar com um orçamento enxuto.

Visando identificar, diante deste cenário, as intenções da Prefeitura com o projeto do Blocódromo, nos deparamos com outra ação do município relacionada ao carnaval: o corte do valor da subvenção das escolas de samba ${ }^{14}$, anunciado meses antes, em julho de 2017. Mesmo que a Arena Carnaval Rio não trouxesse custos aos cofres públicos, a ideia deste evento já revelava uma preferência da municipalidade pelos blocos de carnaval em relação aos desfiles da Sapucaí, uma vez que, naquele ano, não houve os já tradicionais ensaios técnicos das escolas de samba no Sambódromo e nem projeto da Prefeitura para realizá-lo. Esta aparente preferência pelos blocos é ainda mais curiosa, se observada a articulação feita durante a campanha eleitoral para a Prefeitura da Cidade do Rio de Janeiro, em 2016. Entendidas como importantes mobilizadoras sociais, boa parte das escolas de samba optou por declarar apoio ao candidato Marcelo Crivella, que acabou sendo eleito, enquanto os integrantes dos blocos desfilavam ao lado do outro candidato, segundo colocado, Marcelo Freixo (Alfano, Nunes \& Lins, 2016, p. 15).

Alvo das críticas dos blocos, Marcelo Crivella seria "homenageado" no samba do Simpatia é Quase Amor, em 2018. Apesar de não citá-lo diretamente, a composição's sugeria, através de rimas e menções a medidas atribuídas ao prefeito (e bispo da igreja Universal), a "adivinhação" do seu nome: "Ensaio de escola? Ele mela / Roda de samba? Atropela / Macumba? Não tolera / Só gosta de bloco Nutella ${ }^{16}$ / Ele não cuida? Nem zela / Casa de jongo? Cancela / Em nome de Deus? Apela / Qual o nome do hômi?". Seguindo a mesma premissa, Fernandes e Barroso (2018, p. 116) enxergavam a proposta do blocódromo como mais uma das tentativas da atual gestão municipal de "desestimular atividades culturais de rua que já acontecem de forma plena, nos formatos mais espontâneos e orgânicos na cidade".

Ainda segundo Fernandes e Barroso (2018, pp. 115-116), um destes projetos, ainda não implementado, era o dos Distritos Culturais, que previa a reserva de espaços específicos para a atividade cultural de rua, onde eventos públicos e gratuitos poderiam acontecer sem a necessidade de alvará da prefeitura. Segundo a então secretária de Cultura, Nilcemar Nogueira, entre estes distritos estariam: a Rua Álvaro Alvim, onde funciona o Rivalzinho, bar com música de rua e gratuita que foi recentemente interditado pela prefeitura (Guimarães, 2017, p. 2); a Pedra do Sal, onde há rodas de sambas que frequentemente sofrem represálias de agentes públicos ${ }^{17}$; no Ponto Chic, em Padre Miguel, na Zona Oeste; na Praça Tiradentes, palco da roda de samba Pede Teresa, vetada pela

\footnotetext{
${ }_{14}$ O jornal O Globo (Marinatto, 2018, p. 9), apontava que os quase 3,3 milhões a serem investidos na Arena Carnaval Rio superavam a verba pública utilizada na viabilização de novas unidades de educação infantil. A intenção com essa comparação era a de usar o mesmo argumento do prefeito Marcelo Crivella quando reduziu, pela metade, a subvenção direcionada às escolas de samba do Grupo Especial, em julho de 2017, alegando transferir estes valores para as creches municipais.

${ }^{15}$ A composição, de Manu da Cuíca, Luiz Carlos Máximo, Belle Lopes e Bil-Rait Buchecha, está disponível em https://www. youtube.com/watch?v=d1]oGPiEahE

${ }^{16} \mathrm{~A}$ gíria "Nutella" é comumente aplicada àquilo que se deseja criticar por seu "excesso" de requinte.

${ }_{17}$ Matéria de jornal Extra intitulada "Pedra do Sal cancela roda de samba e responsabiliza guarda municipal que nega intervenção". Retirado de https://glo.bo/2PljxnC
} 
Polícia Militar (Gois, 2017, p. 10); e no Aterro do Flamengo, onde o ensaio do bloco Tambores de Olokun foi paralisado por um agente da Superintendência da Zona Sul (Boere, 2017, p. 16):

não existe, de fato, a intenção de fomento a essas atividades, mas uma tentativa de controle e vigilância. Além disso, outros espaços de intensa produção da cultura de rua não foram considerados. A região da Zona Norte que corresponde a $42 \%$ da população do Rio de Janeiro (...) não foi considerada no projeto dos Distritos Culturais. (...) Através da justificativa de melhor distribuição e organização dos eventos de rua, incentivada pela ideia de modernização, os agentes de controle passam a pré-determinar espaços públicos possíveis para aprimorar a vigilância das atividades culturais. Ao reduzir as possibilidades de produção das festas de ruas a locais selecionados, torna passível que outras atividades sejam legitimamente reprimidas. Desse modo, substitui-se a represália ostensiva dos agentes públicos, como Guarda Municipal e Polícia Militar, através de políticas que enfraquecem o alcance das atividades no território. (Fernandes \& Barroso, 2018, pp. 116-117)

Neste contexto, o projeto Arena Carnaval Rio, como uma iniciativa da Prefeitura (e não dos blocos), se não propunha a alteração dos locais de desfiles - discurso defendido pela municipalidade e contestado pela Folha de São Paulo (Rangel, 2017, p. B7) -, pode ser entendido como uma forma de apropriação mercadológica. Esta hipótese ganha mais sentido ainda quando a Riotur anuncia que os blocos participantes não receberiam cachê para se apresentar ${ }^{18}$ (Boere, 2017, p. 5). Para Cássio Novo, especialista em gestão e estruturação do espaço geográfico, projetos como a Arena Carnaval Rio revelam os interesses de grupos ansiosos por lucrar com a privatização de espaços públicos. Em suas palavras:

[o interesse desses grupos] evidencia as estratégias de apropriação dos modos de festejar populares transformando-os (ainda mais) em mercadoria, limitando a cidade a mais um empreendimento racional e cooperando para a promoção do processo de financeirização das nossas vidas. (Novo, 2018, p. 8)

Neste sentido é interessante observar a ideia da Arena Carnaval Rio como um paradoxo em que a festa carnavalesca, que propõe a inversão da ordem social está sendo articulada aos interesses econômicos de quem visa manter esta ordem, o poder público. Do mesmo modo, segundo Rita Fernandes (citada em Frydberg, 2014. p. 10), a partir do "boom" atual do carnaval de rua são criados novos blocos exclusivamente com intuito comercial: "é pegar o que que está na moda, que tipo de música que vende mais, onde eu vou conseguir colocar mais gente na rua, onde meu patrocínio vai ser maior e eu vou conseguir ganhar mais dinheiro".

\footnotetext{
${ }_{18}$ Posteriormente, segundo O Globo, o projeto passou a prever cachês artísticos (Boere \& Magalhães, 2018, p. 10).
} 
É importante observar neste processo de mercantilização da festa que seria leviano reduzir o interesse comercial aos patrocinadores, órgãos públicos e novos blocos. A partir do sucesso do carnaval de rua do Rio de Janeiro no início do século XXI, como aponta Herschmann (2013), muitos dos blocos tradicionais passaram a ser convidados a se apresentar em eventos privados. Estes movimentos de aproximação, que incluem também as festas produzidas pelos próprios blocos e a entrada de profissionais da noite carioca nestas agremiações ${ }^{19}$, revelam como esta distância entre os termos "bloco" e "festa" tem diminuído cada vez mais. Assim, é importante questionar discursos como o de que existem blocos puramente comerciais contra outros "preocupados com os aspectos culturais", uma vez que estas definições são mutáveis e sempre carregam os modos de enxergar a festa do grupo que realiza a crítica.

Por um lado, existe o efeito, alinhado à crítica de Rita Fernandes, onde algumas festas criaram seus "próprios blocos", tais como o Treta Bloco ${ }^{20}$, o Candybloco ${ }^{21}$ e o Bloco da Mug ${ }^{22}$, gerando novos debates sobre a nomenclatura "bloco", uma vez que muitos destes eventos são fechados, pagos e que, ao invés de utilizarem bandas ou orquestras, empregam apenas DJs. Por outro lado, Segundo O Globo, temos - no mesmo ano do projeto do Blocódromo -, um evento na Casa França-Brasil intitulado CasaBloco, que promoveu, bailes carnavalescos, incluindo o Baile da Sebastiana - liga presidida pela própria Rita Fernandes - com shows dos blocos Quizomba e Suvaco de Cristo (Sem sair do quadrado, 2018, p. 7).

Neste sentido, podemos sugerir que a condenação à mercantilização da festa diz respeito mais sobre quem opera a iniciativa do que sobre a proposta em si. Logo, revela-se imprescindível observar as críticas ao Blocódromo não apenas diante das características estruturais do projeto, mas, também, levando-se em conta quem o idealizou. Assim, a falta de diálogo com aqueles que fariam a festa, os blocos, ressoa como um fator decisivo para o fracasso da proposta.

\section{O BLOCÓDROMO - A NEGOCIAÇÃo}

Rodeado de críticas, o engavetamento do projeto Arena Carnaval Rio seria anunciado quase um mês após a sua primeira divulgação à imprensa. Segundo a versão oficial, de acordo com O Globo, após conversa com patrocinadores e a Associação Brasileira da Indústria de Hotéis $(A B I H)$, a proposta seria reformulada e sua realização adiada

\footnotetext{
${ }^{19}$ A ideia de uma folia carioca repaginada por blocos noturnos, ecléticos e com "cara de festa", como o Minha Luz é de Led, formado pela Banda Biltre, é apresentado em https://g1.globo.com/rj/rio-de-janeiro/carnaval/2018/noticia/musa-do-minha-luz-e-de-led-diz-que-bloco-representa-nova-tendencia-do-carnaval-do-rio.ghtml

${ }^{20}$ A festa "Treta", criada em 2014, realizou a estreia do seu Treta Bloco em 2018, anunciando, inclusive, mesmo que não constando na lista da Prefeitura, que estava entrando "oficialmente" para a programação de blocos do carnaval carioca, como pode ser visto em www.facebook.com/events/1973097796288365/

${ }^{21}$ Apresentado como o "primeiro e único" camarote gay da Sapucaí, o Candybox criou o seu próprio bloco de carnaval em 2017 (Guimarães, 2017, p. 2).

${ }^{22}$ A festa de música brasileira, "MUG", passou a realizar bailes intitulados "Bloco da Festa MUG", como visto em O Globo (Bailes e ensaios, 2018, p. 16).
} 
para o mês de julho, transformando-se em um evento carnavalesco "fora de época", visando atrair novos turistas (Prefeitura fará do Blocódromo uma festa julina, 2018, p. 10). Segundo Helaide Teixeira, presidente da Banda da Barra, a liga de blocos da Barra (SamBare) promoveria eventos fora de época na Arena Carnaval Rio, o que a Riotur teria aprovado (Callegari, 2018, p. 12). Deste modo, o projeto ganhava indiscutível caráter mercadológico, visando estimular a turistificação da festa.

Meses depois, ao invés de ganhar vida na Barra da Tijuca, o Blocódromo ocupava, novamente as páginas dos jornais. Reformulado, o projeto voltava a deliberar sobre os desfiles durante o carnaval. Um pouco mais atento à geografia da festa, desta vez, 11 megablocos (os que congregam mais de 200 mil foliões cada um) teriam um único local de desfile, a Rua Primeiro de Março, no Centro. A estrutura, sem catracas ou arquibancadas, utilizaria grades ou bloqueios de concreto, ao longo dos quase $3 \mathrm{~km}$ entre a igreja da Candelária e a Avenida Presidente Antônio Carlos. Seriam realizadas revistas nos foliões, proibindo a entrada com armas brancas e garrafas de vidro. A expectativa era receber um público de até um milhão de pessoas e propunha o desfile de um megabloco por dia (Caruso, 2018, p. 2).

Vale salientar que, desta vez, o novo Blocódromo surge como fruto de uma longa discussão, que chegou a cogitar a Praia de Botafogo (descartada pela necessidade de interrupção do trânsito em vias expressas) e a avenida Presidente Vargas, no Centro (rejeitada pelo fluxo dos carros alegóricos para os desfiles na Marquês de Sapucaí), para a sua implementação. Diferentemente da proposta anterior, a discussão sobre o novo projeto, que durou três meses, contou com a participação dos representantes dos blocos (Prefeitura fará 'blocódromo' no Centro para tirar desfiles da orla, 2018, p. 7).

Apesar disso, dias depois, a proposta sofreria um revés. Os órgãos de patrimônio (Instituto do Patrimônio Histórico e Artístico Nacional-IPHAN, Instituto Rio Patrimônio da Humanidade-IRPH e Instituto Estadual do Patrimônio Cultural-Inepac) mostravam-se preocupados com o fluxo estimado em um milhão de pessoas, o impacto nas edificações e o risco de vandalismo no trajeto que conta com pelo menos nove bens culturais tombados, entre eles, a Igreja de Nossa Senhora do Carmo (antiga catedral metropolitana), o Paço Imperial, o Centro Cultural Banco do Brasil (CCBB) e a Assembleia Legislativa do Estado do Rio de Janeiro (Oliveira, 2018, p. 6).

"Não é bloco de rua, com bateria no chão. São trios elétricos", apontava Mônica da Costa, superintendente do Iphan. Como solução, os órgãos de patrimônio propunham a avenida Presidente Antônio Carlos, próxima ao local e que dispõe de vias mais largas (Caruso, 2018, p. 6). Durante a contenda, o diretor do Inepac, Marcus Monteiro, ameaçou acionar o Ministério Público Federal e Estadual (Oliveira, 2018, p. 6).

No fim das contas, mais uma vez o Blocódromo não saiu do papel. O Iphan fechou acordo com a Prefeitura para que se erguessem grades de alumínio de até 2,20 metros em torno dos prédios históricos, e que os desfiles (de alguns superblocos) se restringissem ao trecho da avenida Antônio Carlos. A rua Primeiro de Março serviu apenas de área de apoio, com estacionamento de ambulâncias do Corpo de Bombeiros (Couto, 2019, p. 10). O interessante desta decisão é que o mais antigo bloco carnavalesco em atividade, o 
Cordão da Bola Preta, há anos ocupa a rua Primeiro de Março para a realização de seus desfiles, que só em 2018 alcançou um público estimado em 1 milhão e meio de pessoas (Cardoso, 2018, p. 10). Deste modo, o novo revés sofrido pelo Blocódromo deixa claro como as decisões relacionadas ao carnaval carioca podem revelar o envolvimento de novos atores e de como estas relações são complexas.

Embora, após dois anos de cancelamento, possa parecer frustrado o projeto do Blocódromo, é interessante observar como este processo não se encerrou ali. Para além da possibilidade de uma nova proposta semelhante, que não pode ser descartada, uma vez que os conflitos que motivaram o projeto não cessaram, talvez o mais interessante a ser observado é como a ideia pode ter inspirado outros eventos semelhantes. Em 2019, por exemplo, os ensaios abertos do bloco Agytoê foram realizados no Passeio Ernesto Nazareth $^{23}$, uma área ao ar livre, na região portuária, cercada para o evento que, mesmo gratuito, exigia a retirada de ingresso através da internet, um modo de regular a lotação. $\mathrm{Na}$ entrada, formou-se uma longa fila para controle de acesso e revista dos foliões ${ }^{24}$. Embora a proposta se apresentasse mais democrática que o ensaio aberto do ano anterior ${ }^{25}$, realizado em local fechado, com cobrança de ingresso, não seria este um exemplo da Arena Carnaval Rio adaptada?

Este relato serve para, mais uma vez, nos lembrar a capacidade de negociação dos atores envolvidos nos processos culturais. Parece irônico, mas é possível observar que um projeto como a Arena Carnaval Rio, acusado de se apropriar de uma manifestação carnavalesca, possa servir de inspiração para os próprios blocos. Através destas supostas contradições, Storey (2015) argumenta que a tarefa da prática crítica não é tentar medir e avaliar a coerência de um texto ou prática, rompendo com a ideia de que ele deva conter uma unidade harmoniosa. O autor prefere sugerir a explicação destas disparidades, que apontem para um conflito de significados. Ou seja, ao invés de apenas destacar estas incoerências, podemos buscar suas motivações e influências.

Neste sentido, como pudemos observar ao longo deste artigo, as semelhanças entre projetos que congregam apresentações de blocos carnavalescos fora do espaço público nos servem para, ao avaliar os discursos a eles relacionados, observar fatores como o local de realização e sua relação com a festa, a autoria da iniciativa, a sua não implicação com o fim da folia de rua, entre outros.

Os blocos de carnaval, conjunto de organizações carnavalescas tão diversas, sejam eles interessados em capitalizar ou não, têm consciência do valor que possuem para a cidade. Seja através de propostas como a Arena Carnaval Rio, seja por meio do uso indevido de suas marcas $^{26}$, mas, principalmente, através do patrocínio obtido pela Prefei-

\footnotetext{
${ }^{23}$ Retirado de https://www.facebook.com/events/310429579579678/

${ }^{24}$ Detalhes observados pelo autor deste trabalho ao frequentar o evento em 20 de janeiro de 2019.

${ }^{25}$ Retirado de https://www.facebook.com/events/216636892228205/

${ }^{26}$ No dia 5 de março de 2019 o Cordão do Boitatá publicou um comunicado em seu Facebook sobre o uso indevido de sua marca pela cervejaria Antarctica. Retirado de https://www.facebook.com/cordaoboitata/ posts/2546402015430299?hc_location=ufi.

Já a festa Salve Guanabara promoveu o evento utilizando imagens do desfile do bloco Boi Tolo. Retirado de https://www. facebook.com/SalveGuanabara/videos/2352826818074465/
} 
tura para viabilizar a organização dos desfiles, os blocos de carnaval perceberam que o discurso a eles relacionado é, muitas vezes, equivocado. Estando os desfiles carnavalescos amparados pelo direito de livre reunião em local público, como aponta a Constituição Federal, logo, não é a Prefeitura que capta patrocínio para viabilizar a estrutura dos desfiles, são os blocos que despertam o interesse de patrocinadores, fazendo com que a Prefeitura negocie e lucre com estas entidades carnavalescas. Deste modo, para projetos como o Blocódromo vingarem, o mínimo que se espera é que se inclua nas discussões aqueles que darão a estas ideias razão para existir.

\section{CONSIDERAÇÕES FINAIS}

A sucessão de tensões e embate de discursos descritos neste artigo ajudam a revelar que a ideia de um Blocódromo surge como mais uma etapa do processo de "ordenação" do carnaval - no qual podemos citar, também a implementação do decreto municipal de 2009, que passou a delimitar novas normas para a realização do carnaval de rua, procedimento que prevalece até hoje. Logo, não se trata de um fato isolado, mas uma maneira de certa parcela da sociedade reafirmar o seu modo de significar o espaço público. Através do projeto Arena Carnaval Rio, observa-se a materialização das críticas de moradores incomodados com a folia de rua, a visão ordenadora da Prefeitura e o potencial mercadológico dos blocos de carnaval.

Através da observação das inúmeras tentativas de criação de um Blocódromo mesmo aquelas que não chegaram a se estruturar -, também percebemos como estas iniciativas articulam muitas tensões, envolvendo diversos atores. Do mesmo modo, as reformulações do projeto, assim como a captação de algumas de suas ideias - até pelos próprios blocos - revelam como essa relação é dialógica, não binária, permeável para trocas.

Analisar os diferentes modos de significar o espaço público, desde os tempos coloniais, observando a influência de fatos como as transformações ocorridas na cidade do Rio de Janeiro, tanto para receber a família real em 1808, como a Copa do Mundo de 2014 e os Jogos Olímpicos e Paralímpicos de 2016, nos servem para entender as motivações relacionadas às mudanças do sentido social mediado pela experiência com os lugares da cidade (Barroso \& Gonçalves, 2016).

Através destas disputas de espaço e sentido, mesmo em projetos aparentemente malfadados, a folia carioca se desenvolve, se reconfigura e se ressignifica, num processo que catalisa interesses tão diversos quanto o dos grupos que congregam o que se habituou chamar de bloco de carnaval. Um movimento que se justifica através de sua vitalidade.

\section{REFERÊNCIAS}

Alfano, B., Nunes, M., Lins, M. N. (2016, 23 de outubro). Presidentes das escolas de samba anunciam apoio a Crivella. Já integrantes de blocos desfilam ao lado de Marcelo Freixo. Extra, p. 15. 
Amar, P. (2018). O arquipélago da segurança: estados de segurança humana, políticas de sexualidade e o fim do neoliberalismo. Rio de Janeiro: Editora UFRJ.

Araújo, H. (2003). Carnaval: seis milênios de história. Rio de Janeiro: Gryphus.

Bacelar, C. (2017, 27 de dezembro). 'Blocódromo' ganha forma. O Globo, p. 5.

Bailes e ensaios. (2018, 16 de fevereiro). O Globo, Rio Show, p. 16.

Barros, M. T. G. M. de (2013). Blocos: vozes e percursos da reestruturação do carnaval de rua do Rio de Janeiro. Dissertação de mestrado, Fundação Getúlio Vargas, Rio de Janeiro, Brasil. Retirado de http://bibliotecadigital.fgv.br/dspace/bitstream/handle/10438/11038/RelatorioFinal_TeresaGuilhon. pdf? sequence $=1$

Barroso, F. M. \& Gonçalves, J. (2016). Subversão e purpurina: um estudo sobre o carnaval de rua não-oficial do Rio de Janeiro. Comunicação apresentada no XXXIX Congresso Brasileiro de Ciências da Comunicação, São Paulo.

Boere, N. (2017, 24 de outubro). Cultura vai ganhar cinco quadriláteros. O Globo, p. 16.

Boere, N. \& Magalhães, L. E. (2018, 10 de janeiro). Bahia que não me sai do pensamento... O Globo, p. 10.

Boschi, M. R. (2007). O carnaval como fenômeno de atração e retenção de turistas na cidade do Rio de Janeiro: um olhar sobre grupos distintos de foliões de blocos da Zona Sul da cidade. Dissertação de mestrado, Fundação Getúlio Vargas, Rio de Janeiro, Brasil. Retirado de https://bibliotecadigital.fgv.br/dspace/ bitstream/handle/10438/3893/ACF28A.pdf

Callegari, C. (2018, 22 de fevereiro). Nota dez no quesito evolução. O Globo, Caderno Barra, p. 12.

Canclini, N. G. (2008). Culturas híbridas: estratégias para entrar e sair da modernidade. São Paulo: Edusp.

Cardoso, L. (2018, 11 de fevereiro). Blocos levam multidões às ruas. O Dia, p. 10.

Caruso, M. (2018, 10 de junho). Carnaval do Rio terá 'blocódromo'. O Globo, Segundo Caderno, p. 2.

Caruso, M. (2018, 30 de junho). Blocódromo na berlinda. O Globo, Segundo Caderno, p. 6.

Caruso, M. (2018, 26 de novembro). Quando a gente conhece o fundo do poço, aprende. O Globo, Segundo Caderno, p. 2.

Constituição da República Federativa do Brasil (1988). Brasília.

Couto, M. (2019, 29 de janeiro). O bloco da Antiga Sé é campeão no carnaval. O Globo, p. 10.

Fernandes, C. \& Barroso, F. M. (2018). Os limites da rua: uma discussão sobre regulação, tensão e dissidência das atividades culturais nos espaços públicos do Rio de Janeiro. Pol. Cult. Rev., 11(1), 100121. https://doi.org//10.9771/pcr.v11i1.26706

Fernandes, R. (2014, 10 de março). Sem generalização. O Globo, p. 12.

Ferreira, F. (2012). Escritos carnavalescos. Rio de Janeiro: Editora Aeroplano.

Ferreira, F. (2004). O livro de ouro do carnaval brasileiro. Rio de Janeiro: Ediouro.

Ferreira, F. (2018, 7 de janeiro). 'Blocódromo' pra quem? O Globo, p. 19. 
Ferreira, J. C. V. (2018). Blocos de enredo: seu lugar e seus significados na configuração do carnaval carioca. Tese de doutoramento, Universidade Federal do Estado do Rio de Janeiro, Rio de Janeiro, Brasil. Retirado de http://www.memoriasocial.pro.br/documentos/Teses/Tese89.pdf

Filho, S. P. L. (2011, 9 de março). Carnaval de muitas críticas. O Globo, p. 8.

Frydberg, M. B. (2014, agosto). Seguindo o cordão: uma etnografia das trocas nos blocos de carnaval de rua na cidade do Rio de Janeiro. Comunicação apresentada na $29^{\text {a }}$ Reunião Brasileira de Antropologia, Natal.

Gois. A. (2017, 21 de outubro). Tempos sombrios. O Globo, p. 10.

Guimarães, C. (2017, 20 de outubro). Está difícil curtir a rua. O Globo, Segundo Caderno, p. 2.

Guimarães, C. (2017, 10 de novembro). Aliás e a propósito. O Globo, Segundo Caderno, p. 2.

Guimarães, H. (2011). Batalhas de confete e coretos carnavalescos: o desenho de uma paisagem efêmera no carnaval carioca nas décadas de 1930 e 1950. Textos escolhidos de cultura e arte populares, 8(2), 259-272. https://doi.org//10.12957/tecap.2011.10441

Herschmann, M. (2013). Apontamentos sobre o crescimento do carnaval de rua no Rio de Janeiro no início do século 21. Revista Brasileira de Ciências da Comunicação, 36(2), 267-289. https://doi.org//10.1590/ S1809-58442013000200013

Informe JB (1981, 23 de abril). Jornal do Brasil, p. 6.

Leopoldi, J. S. (2010). Escolas de samba, blocos e o renascimento da carnavalização. Textos escolhidos de cultura e arte populares, 7(2), 27-44. https://doi.org//10.12957/tecap.2010.11996

Magalhães, S. (2011, 12 de março). O núcleo e a essência do Rio. O Globo, p. 7.

Marinatto, L. (2018, 19 de janeiro). Prefeitura gastou mais com blocódromo do que com creches. O Globo, p. 9.

Marta, F. (2006, 5 de março). A vez do 'blocódromo'. Jornal do Brasil, p. A14.

Motta, A. A. (2011). Blocos de rua do carnaval do Rio de Janeiro. Rio de Janeiro: Réptil.

Novo, C. (2018, 7 de julho). Eu quero é botar meu bloco na rua. O Dia, p. 8.

Oliveira, G. (2018, 2 de julho). Órgãos de patrimônio são contra ‘blocódromo' na Primeiro de Março. $O$ Globo, p. 6.

Prefeitura fará 'blocódromo' no centro para tirar desfiles da orla (2018, 11 de junho). O Globo, p. 7.

Prefeitura fará do blocódromo uma festa julina (2018, 24 de janeiro). O Globo, p. 10.

Prestes Filho, L. C. (2015). O maior espetáculo da terra: 30 anos de sambódromo. Rio de Janeiro: Lacre Editora.

Queiroz, M. I. P. de (1999). Carnaval brasileiro: o vivido e o mito. São Paulo: Brasiliense.

Rangel, S. (2017, 4 de setembro). Rio terá 'blocódromo' no carnaval em área olímpica contra confusão na Barra. Folha de São Paulo, p. B7.

Riotur (2018). Agenda dos blocos de rua do Rio de Janeiro de 2018. Rio de Janeiro.

Saconi, J. P. (2018, 16 de janeiro). Lista oficial de blocos é divulgada para os foliões. O Globo, p. 10. 
Schechner, R. (2012). The future of the ritual. In Z. Ligiéro (Ed.), Performance e Antropologia de Richard Schechner (pp. 155-196). Rio de Janeiro: Mauad X.

Sem sair do quadrado (2018, 9 de fevereiro). O Globo, Caderno Rio Show, p. 7.

Storey, J. (2015). Teoria cultural e cultura popular: uma introdução. São Paulo: Edições Sesc.

Ventura, Z. (2011, 12 de março). Cinzas do carnaval. O Globo, p. 7.

\section{NOTAS BIOGRÁFICAS}

Tiago Luiz dos Santos Ribeiro é doutorando em Artes pela Universidade do Estado do Rio de Janeiro. Carnavalesco e ator; Mestre em Artes pela Universidade do Estado do Rio de Janeiro; Graduado em Comunicação Social (Jornalismo e Publicidade) pelo Centro Universitário Augusto Motta.

ORCID: https://orcid.org/0000-0002-0908-471X

Email: tiago_cinema@hotmail.com

Endereço: Rua Vicente Licínio, 170 ap. 303, Tijuca, Rio de Janeiro, CEP: 20270-340, Brasil

Felipe Ferreira é professor do curso de Artes e dos programas de pós-graduação em Artes (PPGARTES) e em História da Arte (PPGHA) do Instituto de Artes da Universidade do Estado do Rio de Janeiro (UERJ), Doutor em Geografia Cultural (UFRJ) com pós-doutorado em Letras (Sorbonne Nouvelle - Paris III), Mestre em Artes (UFRJ) e Bacharel em Artes Cênicas (UFRJ).

ORCID: https://orcid.org/oooo-0002-5023-5479

Email: felipeferreira@pobox.com

Endereço: Rua Tonelero, 261 ap. 201, Copacabana, Rio de Janeiro, RJ, CEP: 22030००1, Brasil

\section{Submetido: 14.05.2019}

Aceite: 07.10.2019 